Original Research Article

\title{
Evaluation of an appraisal regarding the establishment of Drug Information Service Center in the medical institution
}

\author{
Dattatray Sampatrao Bavane*, Prashanth Chary Ramoji, Santosh Gursale, \\ Rahul Bhavsar, Subhash Nanaware
}

Department of Pharmacology, B. K. L. Walawalkar Rural Medical College, Dervan, Sawarde, Chiplun, Ratnagiri, Maharashtra, India

Received: 25 October 2017 Accepted: 24 November 2017

\section{*Correspondence to:}

Dr. Dattatray Sampatrao

Bavane,

Email: dattabavane@gmail.com

Copyright: (C) the author(s), publisher and licensee Medip Academy. This is an openaccess article distributed under the terms of the Creative Commons Attribution NonCommercial License, which permits unrestricted noncommercial use, distribution, and reproduction in any medium, provided the original work is properly cited.

\begin{abstract}
Background: India has an exploding drug market in generic and brand name products with variable cost. Many doctors tend to rely on pharmaceutical representatives for their prescribing information. Now it is agreed that the major objectives of DISC are to provide a rational basis for choosing and using drugs skilfully to relieve patient's ailments. This is becoming more and more important as the practicing doctors is now confronted with so called "newer drugs" at such a great pace that even a full- time pharmacologist sometimes finds it difficult to keep abreast of their merits and demerits. The DISC provides the knowledge of number of drugs for practical application while prescribing. To provide healthcare professionals and patients with immediate access to accurate, concise and unbiased information on drug therapy problems.

Methods: This is randomized study is to be conducted to determine the opinions of doctors, medical students, nurses, patients, other non-medical staff and general public as a patient representation from our institute campus regarding necessity of drug information. They are provided written feedback forms to be filled. The drug information service center (DISC) routinely responds to queries/inquiries regarding various drug related information. A structured eleven points questionnaire containing both open and close ended questions is prepared for opinion poll in feed-back form.

Results: Large majority of the health and non-health professionals of opinion poll are in favour of reforms \&innovations. They also suggested their own suggestions regarding the refreshing the subjects.

Conclusions: It is essential to create awareness of the services provided by the DISC among physician's pharmacists, nurses and consumers so that they should come forward to utilize these services.
\end{abstract}

Keywords: Drug information service centre (DISC), Pharmacology

\section{INTRODUCTION}

India has an exploding drug market in generic and brand name products with variable cost. Many doctors tend to rely on pharmaceutical representatives for their prescribing information. But due to poor drug regulation, lack of independent and unbiased drug information for doctors contribute to irrational use of drugs. Now it is agreed that the major objectives of DISC are to provide a rational basis for choosing and using drugs skilfully to relieve patient's ailments. This is becoming more and more important as the practicing doctors is now confronted with so called "newer drugs" at such a great pace that even a full- time medical pharmacologist sometimes finds it difficult to keep abreast of their merits and demerits. It is highly desirable, to develop a critical outlook towards various drugs to inculcate in clinical practices - as rational therapy. ${ }^{1}$ 
The DISC provides the knowledge of number of drugs for practical application while prescribing.

Time has now come to how to select drugs based on evidence. Thus, the primary objective of DISC is to provide basis for therapeutic decision in terms of benefits and risk enabling the doctors to select the most appropriate drug. The DISC is involved in application of pharmacological information for clinical practices but also in pharmacovigilance, good documentation practices, therapeutic drug monitoring wing, new drug delivery system, pharmacogenetics, pharmacogenomics, chronopharmacology reviewing of pharmaco-economics and pharmaco-epidemiology etc.

The proliferation of drugs and dosage forms in the pharmaceutical industries /market has led to the need for DISC to be established in the teaching institute and major hospitals. A DISC is involved in the storage, retrieval and dissemination of drug information to all concerned namely doctors, nurses, pharmacists and patients. WHO suggests independent drug information centers as a core component of national program to promote the rational use of drugs. The rational and effective use of drugs is fundamental requirement. Drug information is the process of providing information on the safe and effective use of the therapeutic and diagnostic pharmaceuticals. All countries require drug information support to optimize the use of pharmaceuticals. For example, inappropriate use of antimicrobials can lead to resistance to effect of drugs / and expenditure on drugs. Also, inappropriate use of drugs is a waste of precious resources and increases risk of avoidable drug toxicity. ${ }^{2}$

All health care professionals require information resources for therapeutic decision support, implementation and monitoring of outcomes. Additional information may be necessary for high-risk groups e.g. Pediatrics, geriatrics, pregnancy, lactation, and in some disease conditions like hepatic and renal diseases. Strategies from drug information can promote drug adherence like drug selection and dosing for minimizing adverse effects and drug-drug, drug-food interactions. For the access of authorities and independent drug information one can go only through drug information and service center. The present work is aimed to assess effectiveness of DISC in clinical practices.

\section{Functions of DISC}

- The primary function of DISC is to respond enquiries from health professionals and public regarding information of drugs. Every enquiry should be handled within a reasonable period of time with possible standards.

- Critical selection, evaluation and utilization of the drug literature.

- Surveillance of clinical experiences of drug use in vast community. Disc can participate in research activities like drug utilization studies and pharmacovigilance in community i.e. pharmaco-epidemiology.

- In some cases, toxicological information is also provided for diagnosis and treatment of poisoning.

\section{Requirements of the DISC}

- Furniture

- Communications-telephones, internet access.

- Computers-including external data backup, printer. Software-forward processing, spread sheets, databases; Photocopier.

- Textbooks MIMS, CIMS, IDR, journals etc.

\section{Personnel}

The number of personnel required will depend on the range of activities offered and the hours of service.

The professional staff should include Medical pharmacologist, pharmacist, computer operator and attenders etc

\section{Ancillary activities of DISC}

- Pharmacovigilance

- Pharmaco-epidemiology

- Therapeutic drug monitoring

- Pharmacogenomics etc.

\section{Objectives}

- To provide healthcare professionals and patients with immediate access to accurate, concise and unbiased information on drug therapy problems.

- To provide services such as formulary management, monographs, medication usage evaluation services, clinical practices guidelines and disease state management services in contractual manner.

- To promote patient care through rational use of drugs.

- To monitor adverse drug reactions.

- To supplement the continuing education of all health care professionals through the publishing and distribution of articles and newsletters which keep clinicians aware of the latest information on drug therapy.

\section{METHODS}

After the departmental ongoing discussion, the questionnaire of the feedback form was designed and finalized. This is randomized study is to be conducted to determine the opinions of doctors, medical students, nurses, patients, other non-medical staff and general public as a patient representation from our institute campus regarding necessity of drug information. They are provided written feedback forms to be filled. The drug information service center (DISC) routinely responds to queries/inquiries regarding: 
- Drug doses and dosage forms

- Choice of the routes of drug administration.

- Drug efficacy

- Pharmacokinetic and Pharmacodynamic principles

- Contra-indications and precautions

- Appropriate therapy for specific patients /disease state.

- Dosing in renal/hepatic diseases.

- Uses of drugs in pregnancy and lactation

- Information on new drugs

- Therapeutic comparisons

- Detection and monitoring of adverse drug reactions, drug-drug and drug food interactions

The mode of enquiry may be personal visit, telephone, external contacts, postal and emails. The answer to the queries will be attended with in a time period stipulated by the staff of the DISC. The sources of drug information being from various text books of Pharmacology, various indexed medical Journals, drug bulletin, British National Formulary, Martindale's the extra pharmacopeia, Harrison's principle of internal medicine, the internet CIMS, MIMS etc.

A structured eleven points questionnaire containing both open and close ended questions is prepared for opinion poll in feed-back form. For better understanding and to opine the poll of non-medical persons, the eleven-point questionnaire is provided in both English and local Marathi language for understanding of the objectives of the DISC. The participants are asked to write down their own name or date or mobile no occupation and address with signature on the feedback form. The participants are also allowed to offer their own recommendations regarding amendments of DISC. The present research work was carried out in the month July-August 2017 at BKL Walawalkar Rural Medical College and Hospital, Kasarwadi, Sawarde, Chiplun, Ratnagiri, Maharashtra, India.

\section{Statistical analysis}

The descriptive statistics was used to analysis of data for the result. The frequencies were shown as a percentage.

\section{RESULTS}

The total number of participants involved in expressing opinion for feedback to establish DISC in medical institution is three hundred ninety-four. The large majority of participants are in favour of establishing DISC.

Some participants also expressed their own views regarding DISC. The salient features of this feedback are meaningful. As many as near about $98.2 \%$ of participants are in favour to obtain pharmacological information from DISC. Near about $97.5 \%$ of participants agree with research activities by DISC. As much as $94.7 \%$ participants are agreeing with the selectivity of drugs for treatment of disease condition by only through DISC.

Table 1: Feed-back form -total of 394 participants number and percentage.

\begin{tabular}{|c|c|c|c|}
\hline $\begin{array}{l}\text { S. } \\
\text { No. }\end{array}$ & Questions for opinion of participants & $\begin{array}{l}\text { No. of } \\
\text { Yes }(\%)\end{array}$ & $\begin{array}{l}\text { No. of } \\
\text { No }(\%)\end{array}$ \\
\hline 1 & $\begin{array}{l}\text { Will it provide optimizing information i.e. safe and effective uses of therapeutic and } \\
\text { diagnostic pharmaceuticals regarding drug dosages, dosage forms and routes of drug } \\
\text { administration, drug efficacy, indications, pharmacokinetic and pharmacodynamic } \\
\text { principles? }\end{array}$ & $387(98.2)$ & $\begin{array}{l}7 \\
(1.8)\end{array}$ \\
\hline 2 & $\begin{array}{l}\text { Can it provide drug selectivity like drug sensitivity done by Microbiology dept. for } \\
\text { infective agents? }\end{array}$ & $373(94.7)$ & $\begin{array}{l}21 \\
(5.3)\end{array}$ \\
\hline 3 & $\begin{array}{l}\text { Will it be helpful for minimizing side effects and noting carefulness regarding contra- } \\
\text { indications, precautions and drug-drug /food interactions? }\end{array}$ & $389(98.7)$ & $\begin{array}{l}5 \\
(1.3)\end{array}$ \\
\hline 4 & $\begin{array}{l}\text { Will It help in research activities? E.g. pharmacoepidemiology i.e. drug utilization } \\
\text { Study in communities. }\end{array}$ & $384(97.5)$ & $\begin{array}{l}10 \\
(2.5)\end{array}$ \\
\hline 5 & $\begin{array}{l}\text { Will it be useful for managing for specific patient /disease state - particularly non- } \\
\text { responding cases? }\end{array}$ & $366(92.9)$ & $\begin{array}{l}28 \\
(7.1)\end{array}$ \\
\hline 6 & Does it play role for rapid support in situations where response time is important? & $352(89.6)$ & $41(10.4)$ \\
\hline 7 & $\begin{array}{l}\text { Does it involve in Pharmacoeconomics i.e. price comparison of drugs for chronic /long } \\
\text { turn disease theory? }\end{array}$ & 365 (92.6) & $\begin{array}{l}29 \\
(7.4)\end{array}$ \\
\hline 8 & Can it provide alternative drug information for allergic patients & $389(98.7)$ & $5(1.3)$ \\
\hline 9 & Will it improve patients compliance /convenience for medication? & $384(97.5)$ & $10(2.5)$ \\
\hline 10 & Can it be valuable resource of new drug development /drugs in pipeline? & $360(91.4)$ & $34(8.7)$ \\
\hline 11 & $\begin{array}{l}\text { Can it extent role in monitoring \& reporting adverse drug reactions i.e. } \\
\text { pharmacovigilance }\end{array}$ & $376(95.4)$ & $18(4.6)$ \\
\hline
\end{tabular}


The majority of $98.7 \%$ participants are eager to minimize side effects through DISC. Only near about $97.5 \%$ and 92.9\% participants understand the importance of DISC regarding research activities and treatment of nonresponding patients. The $89.6 \%$ and $92.6 \%$ participants are requiring understanding role of DISC in treatment in emergency and economic price comparison of drugs for chronic therapy.

The reflection of $98.7 \%$ and $97.5 \%$ participants for providing alternative medicines for allergic patients and convince of therapy through DISC is countable. The participants somewhat differed in opinion regarding new drugs information and pharmacovigilance is $91.4 \%$ and $95.4 \%$ respectively.

Apart from above observations expressed in the feedback form, few important suggestions by participants are:

- DISC should run $24 \mathrm{hrs}$ x7 days

- It should be easily accessible and cheaper.

\section{DISCUSSION}

The opinion poll regarding DISC as expected is meaningful. Feedback is supposed essential to find the research activities to evolve strategy regarding implementation and rearrangement of system.

The health professionals and non-health professionals, patients and patient relatives are showing the positive attitude towards objectives of DISC.

Drug information centre refer speciality to facility specially set aside for, and specializing in the provision of drug information and related issues. The purpose of drug information center is to provide authentic individualized, accurate, relevant and unbiased drug information to the consumers and healthcare professionals regarding medication related inquiries to the nation for health care and drug safety aspects by answering their call regarding the all critical problems on drug information, their uses and their side effects. Apart from that the center also provides in-depth, impartial source of crucial drug information to meet the needs of the practicing physicians, pharmacists and other health care professionals to safeguard the health, financial and legal interests of the patient and to broaden the role of pharmacological information visible in the society and community. The service should include collecting, reviewing, evaluating, indexing and distributing information on drugs to health workers. Drug and poisons information centers are best established within major teaching hospitals. This allows access to clinical experience, libraries, research facilities and educational activities. $^{3}$

Information present in the current paper will not only enlighten the role of drug information center but also focuses on the rational use of drug. The primary mission of the Harrison school of pharmacy drug information centre (DIC) is to improve patient care by providing on demand consultative services. ${ }^{4}$

The overall amount of medical information is growing at an alarming rate even the body of knowledge covering only drug information seems to be endless. There is vast amount of data on drugs that are approved by the food and drug administration (FDA), and on agents undergoing clinical investigation. ${ }^{5}$

There are many sources of information available that can help answer drug related questions. Exercises posted on the web, and the self-paced news group will assist you in developing skills to efficiently utilize resources to better manage your patients drug related problems. ${ }^{6}$

Another part of this research consists of Pharmacoeconomics for knowing price differences for long term therapy, newer drugs in pipeline, treatment of nonresponding cases and minimizing side effects of drugs.

Pharmacovigilance is the science that deals with activities related to the detection, assessment, understanding and prevention of adverse drug reactions. This helps us to evolve policy towards safe and effective use of medicines. So that drug related mortality and morbidity can be prevented or minimized. ${ }^{7}$

The Ministry of Health and Family Welfare (MOHFW) of Government of India has designed a program called National Pharmacovigilance Program of India (PvPI) in the year 2010 under the supervision of Central Drugs Standard Control Organization (CDSCD) and Drug Controller General of India (DCGI) to study response to a drug which is noxious and unintended that occurs at doses normally used in man for the prophylaxis, diagnosis or therapy of disease or for the modification of physiological function and pathological conditions.

As of now this activity is carried out in 60 centers in Medical Colleges in India. MCI in its recent recommendation, made it mandatory that all medical colleges should have a functioning Pharmacovigilance centre. $^{8}$

It will be prestigious and significant if MCI broadens their view regarding functioning of pharmacovigilance centers in medical colleges as a part of DISC.

A good relation is observed between the circadian rhythms and the symptoms of certain diseases like asthma, arthritis, allergic rhinitis, sleep disorders etc. Dis-functioning of the body is directly related to the biological clock affecting the function of brain and behavior which is improved by the Chrono-therapeutics approach. Chrono-therapeutics is defined as the study of delivering the medicament in a proper concentration at right time to cure the disproportionality occurring in some circadian rhythms having relatively low biological rhythms to maximize relief from particular diseases. ${ }^{9}$ 
Thus, chronotherapeutic principles should be added in DISC.

Clinical Pharmacology is a relatively young discipline. The term was coined by Harry Gold in 1950s. It involves scientific study of drugs in man, their rational use which includes personalized medicine, safety and efficacy of medicines, consideration to cost, availability, etc. Against this current scenario, there are a large number of future changes and challenges, both on the national as well as the global scenes. Dr. C. T. Dollery, a world-renowned expert and one of the pioneers in Clinical Pharmacology from $\mathrm{UK}$, has reviewed Clinical Pharmacology growth. There is a surge in the country in the development of new technologies (e.g. information technology and nanotechnology). The Government of India has declared 2011-2020 as the decade of innovation to find new solutions in many areas to achieve our goals of inclusive and sustainable growth in healthcare, energy, urban infrastructure, water management and transportation. ${ }^{10}$

Now it is generally agreed that the major objectives of teaching pharmacology to the medical students is to provide a rational basis for choosing and using drugs skilfully to relieve patient's aliments.

"What aspects pharmacology should be given due importance for an undergraduate student as Therapeutics? Or clinical pharmacology? Or experimental pharmacology?".

While clinical pharmacology encompasses only scientific study of pharmacokinetic and Pharmacodynamic principles of both old and new drugs in healthy volunteers and patients for their safety and efficiency in terms of treatment part. This is nothing but clinical trials data.

Therefore, renaming of today's pharmacology as Medical Pharmacology is justifiable. Thus, the main purpose of the medical pharmacology is to deliver sequential pharmacological information for medical undergraduate to develop requisite therapeutic skill in the clinical practices

The ultimate aim of medical pharmacology emphasizes involvement in drug information service centre. ${ }^{11}$

Medicines are now regarded as active substances plus information. There is various drug information centers like drug information specialists manage drug services as by pharmacists and other professional. ${ }^{12}$ There are also pharmaceutical consultations in UAE communities. ${ }^{13}$ Also the Karnataka state pharmacy council established its drug information centre, and which is recognized by international register of drug information services. ${ }^{14}$

One community developmental medicinal unit as a part of NGO at Calcutta reply queries from not only from health care professionals but also from patients side also regarding drug information. ${ }^{15}$ These centers provides guidelines for rational use of drug to promote safe and effective drug therapy.

Founded in 1973, the international drug information center (IDIC) of LIU pharmacy provides evidence-based, up-todate, accurate, and unbiased information about pharmaceuticals and dietary supplements to a varied client base including pharmacists, physicians, nurses, other healthcare professionals, select consumer groups, pharmaceutical companies, attorneys, law enforcement agencies, pharmacy benefit managers, poison control centers, and other institutional and organizational clientele. The IDIC maintains a comprehensive library of resources containing information on US, foreign, and investigational products, as well as information on dietary supplements and herbal remedies. ${ }^{16}$

The purpose of assessing the pattern of drug information queries received by the drug information center (DIC) of a tertiary care teaching hospital in South India is significant. A retrospective review of drug information queries received by the DIC over a period of 8 months was performed. Data were collected for various parameters such as status of enquirer, mode of receipt of query, purpose and type of query, mode of reply, and references used. A drug information queries were from ward rounds, followed by direct access from the Medicine department, Pediatric department and Surgery Department and Post graduate students. The references used for answering the queries were textbooks, Micromedex ${ }^{\circledR}$, database websites and journals. DIC had attempted to provide unbiased information to health care professionals to help improve therapeutic decision making. ${ }^{17}$ There should be continuous ongoing reforms for discovering, interpreting, revising and delivering the current knowledge of the subject relevant to the needs of society as a part of research. The study also evolves Medical pharmacologists for running drug information service centre as pharmacological consultancy as an option to teaching and industry jobs because he/she could better correlate disease condition for therapeutic than pharmacist.

\section{CONCLUSION}

It is essential to create awareness of the services provided by the DISC among physician's pharmacists, nurses and consumers so that they should come forward to utilize these services.

\section{ACKNOWLEDGEMENTS}

Authors would like to thank Sadguru Shri Kaka Maharaj and support provided by Shri Vikas Walawalkar, Dr. Suvarna Patil Medical Director, Dr. Netaji Patil, Dr. Banavali, Dr. Nadkarni, Principal Dr. Dombale, Dr. Moholkar, Dr. P. R. Gade, Dr. Nilekar, Dr. Jaju, Dr. Akram Naikwadi, Dr. Ramkrishna Gade, Dr. Anand Bhosale, Dr. Biarajdar, Dr. S. B. Mane, Mr. Gautam Tendulkar, Mrs. Shrutika typist, Students, Medical and Non-medical staffs, Patients and patient representatives from general public. 
Funding: No funding sources

Conflict of interest: None declared

Ethical approval: The study was approved by the Institutional Ethics Committee

\section{REFERENCES}

1. Satoskar RS, Bhandarkar SD, Rege NN. Pharmacology and pharmacotherapeutics: $13^{\text {th }}$ Ed. Popular Prakashan; 2014.

2. Chauhan N, Moin S, Pandey A, Mittal A, Bajaj U. Indian aspects of drug information resources and impact of drug information centre on community. J Ad Pharma Tech Res. 2013;4(2):84.

3. Drug information center. Available at: http://www.pharmacy.wsu.edu/facultyexperts/drug information center/index. Accessed Feb 2017.

4. Olin B, Baker D. Drug information and learning resources center. Available at: http://pharmacy/auburn. edu,lat. Accessed Feb 2017.

5. Veron G. Requirements for drug information center, FIP pharmacy information section. Available at: www.fip.org. Accessed September 2005.

6. Wooten J. Sources for drug information, Medicine. Available at: http://www.coursehero.com, Accessed on November 2012.

7. Sivananam G. Available at: http://www.hitwebcounter.com. Accessed April 2017.

8. Mishra H, Kumar V. Pharmacovigilance: current scenario in a tertiary care teaching Medical College in North India. J Pharmacovigilance. 2013;2013.

9. Kumar R. Chronotherapy: New approach for the treatment, Mid-East J Sci Res. 2015;23(7):1280-5.
10. Kshirsagar N, Clinical pharmacology: prospectus and development in India, Indian $\mathbf{J}$ Pharmacol. 2011;43(5):489-91.

11. Bavane DS, Naikwadi A. Feel good in the medical pharmacology. Int $\mathrm{J}$ Basic Clinic Pharmacol. 2017;6(9):2177-82.

12. Aqil M. Grooming a competent drug information specialist, Indian J pharmacol. 2004;36(2):96-8.

13. Hamoudi NM. The pharmaceutical consultation in USE Communities. Indian J Pharm Sci. 2011;405-7.

14. Lakshmi PK, Rao DG, Gore SB, Bhaskaran SH. Drug information services to doctors of Karnataka, India. Indian J Pharmacol. 2003;35(4):245-7.

15. Rohit. Evaluation and appraisal of drug information services in a rural secondary level care hospital, Anantapur, APJ. 2012;302-7.

16. Hazra A. One-year experience of drug information service in the NGO sector, Indian $\mathbf{J}$ Pharmacol. 2001;33:44-5.

17. John M, Pezzuto. International drug information center, http://www.liu.edu/pharmacy,IDIC.

18. Puttegowda SB, Lakshiminarayana SY, Ramarathnam NM. Assessing the pattern of drug information queries in a rural South Indian tertiary care teaching hospital. Malaysian J Pharm Sci. 2010;8:1-9.

Cite this article as: Bavane DS, Ramoji PC, Gursale S, Bhavsar R, Nanaware S. T Evaluation of an appraisal regarding the establishment of Drug Information Service Center in the medical institution. Int J Basic Clin Pharmacol 2018;7:197-202. 